\title{
Techno-Economic Feasibility Analysis of Solar Photovoltaic Power Generation: A Review
}

\author{
Majid Jamil $^{1}$, Sheeraz Kirmani ${ }^{1}$, Mohammad Rizwan ${ }^{2}$ \\ ${ }^{1}$ Department of Electrical Engineering, Jamia Millia Islamia, New Delhi, India; ${ }^{2}$ Department of Electrical Engineering, Delhi Tech- \\ nological University, New Delhi, India. \\ Email: majidjamil@hotmail.com, sheerazkirmani@gmail.com,rizwaniit@yahoo.co.in
}

Received January $4^{\text {th }}, 2012$; revised August $7^{\text {th }}, 2012$; accepted September $4^{\text {th }}, 2012$

\begin{abstract}
With the rapid depletion of fossil fuel reserves, it is feared that the world will soon run out of its energy resources. This is a matter of concern for developing countries whose economy heavily leans on its use of energy. Under the circumstances it is highly desirable that renewable energy resources should be utilized with maximum conversion efficiency to cope with the ever increasing energy demand. Furthermore, the global economic and political conditions that tend to make countries more dependent on their own energy resources have caused growing interest in the development and use of renewable energy based technologies. In terms of its environmental advantages, renewable energy sources generate electricity with insignificant contribution of carbon dioxide $\left(\mathrm{CO}_{2}\right)$ or other greenhouse gases (GHG) to the atmosphere and they produce no pollutant discharge on water or soil and hence power generation from renewable becomes very important. Major types of renewable energy sources include solar, wind, hydro and biomass, all of which have huge potential to meet future energy challenges. Solar photovoltaic technology in one of the first among several renewable energy technologies that have been adopted worldwide for meeting the basic needs of electricity particularly in remote areas. In this paper literature review pertaining to techno-economic feasibility analysis of solar photovoltaic power generation is discussed. The literature is basically classified into the following three main category design methods, techno-economic feasibility of solar photovoltaic power generation, performance evaluations of various systems.
\end{abstract}

Keywords: Solar Photovoltaic Power; Techno-Economic Feasibility; Performance Evaluation; System Design Methods

\section{Introduction}

The development of renewable energy sources (RES) is necessary for the sustainable development of any country due to depleting fossil fuel level, climbing fossil fuel prices across the world and more recently pressure for reduction emission level. Among various renewable energy sources based technologies, the photovoltaic technology for power generation is considered well-suited technology particularly for distributed power generation. The large introduction of PV systems may replace or postpone the extension of conventional central stations of electricity production and the investment in grid reinforcement having a positive overall economic impact. The PV system electric power is of particular value when it coincides with the peak demand, as during the summer afternoon peak due to the use of air conditioning units. In addition to this, solar photovoltaic (SPV) systems can also increase the reliability of the system to which they are connected, can also reduce transmission and distribution losses as they generate the electricity close to the point where it is consumed [1]. India has a large land area with an average

Most parts of India receive solar energy of $5 \mathrm{kWh} / \mathrm{m}^{2}$ per day over 280 clear days per annum. Even if $1 \%$ of this land is used to harness solar energy at an overall efficiency of $10 \%$, as much as $429 \times 109 \mathrm{kWh} /$ year of electricity can be generated. In India as on 30th September 2011 there are many solar PV power plants of large and medium ranges $(200,100,50,25 \mathrm{~kW})$ working satisfactorily amounting to approximately 108.66 MWP. This paper basically presents the review of the technoeconomic analysis of solar photovoltaic power generation. This paper is organized as follows: system design methods are discussed in Section 2. In Section 3 review of the techno-economic feasibility of solar photovoltaic power generation is presented. Performance evaluations of various systems are discussed in Section 4. A summary followed by the references is presented in Section 5 .

\section{System Design Methods}

The technical design of a system refers to design of correct sizing of the system with respect to capacity, optimal 
design for increased reliability and improvements in efficiency. The main objective of design of the system is to improve the quality of power for a given load factor and to achieve this in an optimal way. This depends on parameters like the population, demand, and proximity to grid. There is a huge knowledge base available in studies of design of the SPV systems. Different techniques like optimization, simulation and other mathematical modeling tools have been used for this purpose and are discussed below.

Literature presents the methods for component selection and system design. A review of different methods for sizing photovoltaic systems indicates that they fall into mainly two categories, analytical methods and simulation-based schemes. A methodology for the calculation of optimum size of a battery bank and optimum size of a Photovoltaic (PV) array in a hybrid wind/PV system for a given level of reliability of a typical house in Massachusetts is developed [2] and for a given load and a desired Loss of Power Supply Probability, an optimum number of batteries and PV modules was calculated based on the minimum cost of the system. The possibility of wind alone, PV alone and hybrid wind/PV system for a typical residential load in Montana is discussed [3]. Generation and storage units for different system are properly sized in order to meet the annual load and minimize the total annual cost to the customer. In addition, an economic analysis has been performed for the three different scenarios and is used to justify the use of renewable energy versus constructing a line extension from the nearest existing power line to supply the load with conventional power. Annual average hourly values for load, wind speed, and insolation have been used. This work takes into account the economic factors for calculation of optimum component size. In this paper, an economic analysis is performed for realizing the advantage of the stand-alone system versus constructing a line extension from the nearest existing distribution line for supplying the load with conventional power. The sizing and techno-economic optimization of an autonomous hybrid PV/Wind energy system with battery storage is discussed [4]. The study has considered the various aspects e.g. the level of autonomy i.e. the fraction of time for which the specified load can be met and the cost of the system rather than designing the system for the worst month scenario which lead too costly system as done by few researchers the system cost and performance both are taken into account and a third energy source that is a battery is connected in the system to reduce the cost. A method for designing the PV power system respecting the local environmental conditions is discussed [5]. The results of the measurements carried out over two years show the extent to which PV power generation can be matched with load demands and state of battery charge even during periods of low solar radiation. For Ethiopian conditions a method is investigated to find the possibility of supplying electricity from a solar-wind hybrid system to a remotely located model community detached from the main electricity grid. Based upon the solar and wind energy potential feasibility study has been carried out on how to supply electricity to a model community of 200 families, which comprises 1000 people in total. A software tool, Hybrid Optimization Model for Electric Renewables (HOMER) is used for the analysis. The result of the analysis is a list of feasible power supply systems, sorted according to their Net Present Value. Furthermore, sensitivity diagrams, showing the influence of wind speeds, PV costs, and diesel prices on the optimum solutions are also provided [6]. In one of the study a generalised methodology based on a time series simulation approach for generating a "sizing curve" relating the generator rating and storage capacity is presented [7]. This methodology helps in the identification of a design space that explores all feasible system configurations meeting a given demand for a site. It further serves as a tool for system optimization. Using this same approach a methodology for the optimum sizing of photovoltaic battery system for remote electrification incorporating the uncertainty associated with solar insolation is presented [7]. The sizing curve for a given confidence level connects the combinations of the photovoltaic array ratings and the corresponding minimum battery capacities capable of meeting the specified load [8].

A recent model [9] is designed an optimal autonomous hybrid PV-diesel-battery system to meet the load of an off-grid house and concluded that maximum energy is produced during the summer months when the load demand is also maximum and hence the system is most favourable as the use of the hybrid system results in saving of a lot of diesel and hence the effect of GHG is also minimised. The hybrid system with $23 \%$ of photovoltaic energy penetration and comprised of $2 \mathrm{~kW}$ PV array, diesel generator with a rated power of $4 \mathrm{~kW}$ and 2 storage batteries in addition to $2 \mathrm{~kW}$ converter was found to be the optimal system and it becomes economically feasible for diesel prices greater than $0.15 \$ / L$. The monthly average electricity production of the most feasible hybrid system showed that higher electricity production is noticed during the summer months (May-September) as compared to other months. This is a favourable characteristic, because this trend closely matches the load trend which is high during the summer months. Utilizing this system for electricity generation in comparison with the diesel-only situation-decreased the operational hours and consequently the diesel consumption of the diesel generators and led to reduction in emissions of GHG.

Similar approaches of trade-off between loss-of-load or capacity shortage and levelised unit cost of electricity 
for solar home systems (SHS) have been presented for different location in India using HOMER [10]. The study suggests that different system configurations (a combination of PV module and battery capacities) can be used for different load patterns and different applications. A paper for a residential micro-grid user for standalone application the photovoltaic/fuel cell/ultra capacitor (PV/FC/UC) hybrid power system is designed and modelled [11]. To overcome the deficiency of the PV technology that its output is dependent on environmental conditions the PV system is integrated with the FC/UC system using a new topology. A detailed simulation model has been developed using Matlab/Simulink and Sim power systems packages which allows designing and analyzing any PV/FC/UC hybrid system with various power levels and parameters. The system is tested for the varying solar radiation and varying load demand, where the solar radiation and power demand data are based on real-world records. The developed system and its control strategy exhibit excellent performance for the simulation of a complete day or longer periods of time. Applications of Artificial Intelligence (AI) techniques for sizing of solar photovoltaic systems are presented [11]. AI techniques have demonstrated the possibility for sizing PV-systems successfully and with reasonable accuracy. Generally, AI techniques have demonstrated the possibility for sizing PV systems based on some available data successfully and with reasonable accuracy. Literature available on the sizing of PV-systems based on AI techniques indicates their popularity, particularly in isolated areas. This shows the potential of AI as a design tool in the optimal sizing of PV systems. AI based sizing of PV systems has been applied in many countries such as Algeria, Spain, Greece, Ireland, Island and Turkey is presented [12]. Different approaches for biogas/photovoltaic hybrid power system for decentralized application for rural areas in Brazil and provide a short review about the evolution of hybrid power systems at Americas and Caribbean [13]. Genetic algorithm for designing and operational management of a PV-diesel hybrid system and an optimization of PV-diesel hybrid systems for mini-grid for an isolated island sandwitch in Bangladesh is discussed [14]. In this work the electrical load is considered based on the local needs. The design of the system is based upon the fact that if the renewable energy source produces more than the one required by the loads, the excess energy can be used to charge the battery while if the amount of energy demand is higher than the one produced by the renewable energy source, the control strategy determines the most economical way to meet the energy deficit. This study reveals that the major shares of the cost are for solar panels and batteries. Technological development in solar photovoltaic technology and economic production of batteries would make rural electrification in the isolated islands more promising and demanding. The authors in [15] quantified energy losses and the most relevant performance parameters of a $2 \mathrm{~kW}$, grid connected photovoltaic system in Spain. A generalized model is developed which evaluates the performance at different regions, climate conditions and irradiation. A range of $(10,15$, and $30 \mathrm{~kW}$ ) solar-diesel hybrid system micro-grids has been designed which could provide, if implemented, energy to $90 \%$ of the villages in developing countries [16]. In another study [17] it is mentioned that the mount of electricity generated could be increased by the right sizing and alignment of the arrays in a solar PV system by replacing the traditional single aperture system by interconnected arrays. A simulation model is presented to find the right size of stand-alone solar PV systems, the risk associated with failure of power supply is taken into account by a factor called loss of power supply probability (LPSP), which is the probability that the PV modules together with battery will fail to supply power on an arbitrary day. A linear programming model is also used to optimize the number of PV modules and batteries. The importance of dimensioning of a solar-wind hybrid energy system and formalised the procedure of exact determination of the energy potential and demand on site for dimensioning the system configuration is presented in [18].

It has been concluded that while designing the system for various applications and selecting the size of various components correct optimization techniques has to be used. Selecting the correct optimization technique can reduce the system cost for particular application and location.

\section{Techno Economic Evaluation}

The assessment of a particular energy system for its techno-economic feasibility is of utmost importance if the system has to function satisfactorily at a given location. The techno-economic feasibility assessment of a particular technology begins with evaluating the technological appropriateness, economic viability and other financial incentives of a technology for it to get successfully disseminated at a given location.

This section deals with the literature pertaining to the techno economic evaluation of various solar photovoltaic systems. The economic competitiveness of PV systems in developing countries and showed that even after including externality costs, the economics of PV applications are unlikely to allow for an unsubsidized, widespread adoption of this technology in the near future without significant technological breakthroughs [19]. In this work it is concluded that solar photovoltaic systems require further research and development programmes for the improvement in PV panel efficiencies. The 
techno-economic assessment of an autonomous hybrid $\mathrm{PV} /$ diesel for a tourist resort in Elounda has been done [20]. The different economic and financial aspects have also been calculated for different financial scenarios and concluded that the use of solar-energy supply systems imply no compromise for the tourists in terms of comfort, reliability of operation and facilities compared with conventional lodging and renewable systems are mature technologies and provide alternative solutions to the increasing global energy-demand problem [21].

Techno-economic viability of hybrid photovoltaic diesel battery power systems for residential loads in Saudi Arabia has been presented [22]. The analysis highlights several benefits of the hybrid system. Some of these are high utilization rate of PV generation; optimal satisfaction of load; maximum diesel efficiency with minimum maintenance; reliable power supply; and a reduction in the capacities of PV, diesel and battery while matching the peak loads. Emphasis has been placed on un-met load, excess electricity generation, percentage fuel savings and reduction in carbon emissions for different scenarios such as PV diesel without storage, PV diesel with storage, as compared to diesel-only situation. The decrease in carbon emissions by using the above hybrid system is about $24 \%$ as compared to the diesel-only scenario. The economic viability of a standalone PV system in comparison to the most likely conventional alternative system, i.e. a diesel-powered system, has been analysed for energy demand through sensitivity analysis [23]. The analysis shows that PV-powered systems are the lowest cost option at a daily energy demand of up to $15 \mathrm{kWh}$, even under unfavourable economic conditions. When the economic parameters are more favourable, PV-powered systems are competitive up to $68 \mathrm{kWh}$ /day. These comparisons are intended to give a first-order indication of when a stand-alone PV system should be considered for application. As the cost of PV systems decreases and diesel costs increase, the breakeven points occur at higher energy demand. A complete techno-economic feasibility of energy supply of remote villages in Palestine by PV-systems, diesel generators and electric grid has been done [24]. A computer-aided dynamic economic evaluation method with five indicators is used to compare the economic-effectiveness of these energy systems. The results shows that, utilizing of PV systems for rural electrification in Palestine is economically more feasible than using diesel generators or extension of the high voltage electric grid.

A techno-economic evaluation of a hybrid wind/PV/ FC generation system is performed [25] and a computer program is also developed for sizing of the various components of the system and the hybrid/PV/FC system is compared economically with wind/PV/battery storage system for a typical residential load and the breakeven analysis is also carried out and it is observed from the analysis that the traditional wind/PV/battery storage system is more cost effective. Here the combination of a FC stack, an electrolyser, and hydrogen storage tanks is used as the energy storage system. The electrolyser in the FC/electrolyser storage system is used as a part of dump load. When there is excess wind or solar generation, the electrolyser turns on to begin producing hydrogen, which is delivered to the hydrogen storage tanks. If the $\mathrm{H}_{2}$ storage tanks become full, the excess power will be diverted to another dump load. When there is a deficit in power generation, the FC will begin to produce energy for the load using hydrogen from the reservoir tanks. For the wind/PV system with battery storage, the combination of FC/electrolyser, $\mathrm{H}_{2}$ reservoir tanks, and their associated DC/DC converter are replaced with battery banks.

Literature presents several studies on energy pay back time and life cycle analysis of PV technologies. The analyses the PV system with reference to a fuel oil-fired steam turbine and their GHG emissions and costs revealed that greenhouse gases (GHG) emission from electricity generation from the PV system is less than onefourth that from an oil-fired steam turbine plant and one half that from a gas-fired combined cycle plant. From the life cycle energy use and GHG emission perspectives, the PV system is a good choice for power generation. However, it also indicates that large scale exploitation of PV could lead to other types of undesirable environmental impacts in terms of material availability and waste disposal [26].

Life cycle assessment of electricity generation by PV panels considering mass and energy flows over the whole production process starting from silica extraction to the final panel assembling, using the most advanced and consolidate technologies for polycrystalline silicon panel production is presented [27]. Briefly, the most important results of the analysis are the calculation of a gross energy requirement (GER) of $1494 \mathrm{MJ} /$ panel $\left(0.65 \mathrm{~m}^{2}\right.$ surface) and of a global warming potential (GWP) of $80 \mathrm{~kg}$ of equivalent $\mathrm{CO}_{2}$ panel. The energy pay back time (EPBT) has been estimated to be shorter than the panel operation life even in the worst geographic conditions. The results of the LCA support the idea that the photovoltaic electric production is advantageous for the environment. The foreseeable technological advancements in current and emerging PV technologies over the next few decades are likely to lead to significantly lower per-kWh impact than the one that characterizes the current state of the art of the PV sector has been analyzed [28].

A complete techno-economic analysis of standalone solar photovoltaic system has presented [29]. In this work, complete analytical methodology for optimum relationship between PV array and storage battery capacity to supply the required energy at a specified energy 
load fraction is carried out. To estimate the performance of solar photovoltaic system the solar radiation utilizability concept and the monthly average daily PV array efficiency have been used. The techno economic optimization of a PV system has been done by using levelized energy cost computation based on the total number of battery replacements (brp’s) through battery life-cycle model. It has been found that energy load fractions as well as the number of brp's have a significant impact on the selection of optimum sizing of a stand-alone PV system. From the techno-economic and environmental points of view, the feasible sites in Egypt to build a 10 MW PV-grid connected power plant and recommended few sites for large scale PV power generation [30].

The techno-economic analysis of grid connected hybrid wind/PV system is carried out for three different locations in Iraq [31], and it was observed that total amount of energy generated from wind and solar is highest for one location and less for the rest two and it is concluded that in case of solar and wind plant location strongly affect the plant performance. Authors have performed a net present value comparison for north Cameroon between Photovoltaic hybrid system for mini grid application, standalone photovoltaic and standalone diesel generator options for a typical energy demand [32]. A economic comparison of PV/Diesel hybrid power system with battery storage in comparison to diesel generated electricity for a village is performed [33] and found that the hybrid system is more economical in comparison to the diesel only system to meet the energy requirement of a small village Rowdat Ben Habbas located in the north eastern part of the Kingdom and it was observed that the existing diesel generation system is economical as the diesel prices right now is $0.2 \$ /$ Litre. With increasing fuel price the diesel only system was found to becoming less economical and at a fuel price of $0.60 \$ / 1$ and above, the diesel only system became un-economical compared to that of hybrid power system.

A complete techno-economic comparison of rural electrification based on solar home systems and PV micro-grids to supply electricity to rural community for domestic purpose has been performed [10]. Based on study it is concluded that a micro grid might be a financially more attractive option for the user, energy service company and the society if the village has a large number of households, is densely populated and lies in a geographically flat terrain and more than 500 densely located households using 3 - 4 low power appliances (e.g. $9 \mathrm{~W}$ CFLs) for an average of $4 \mathrm{~h}$ daily. However, in rough terrains solar home systems might be a better option if the community is small and sparsely populated. The economic analysis has been performed on the grid connected SPV system connected to the Spanish grid [21]. Using net present value (NPV) and payback period
(PP) parameters, the profitability of the system was studied. The system was evaluated for its economic as well as environmental benefits and the results clearly showed that the system is profitable enough to be invested in, but very long pay back periods were dissuading the investors. The techno-economic assessment has been performed to determine the technical feasibility and economic viability of a hybrid solar/wind installation to provide residences in Greece with thermal and electrical energy [34]. The energy output of the hybrid system was estimated using a simulation model and economic analysis is performed using Life Cycle Costing (LCC) method, the payback period. A strong case of stand alone SPV systems has been built by conducting feasibility study in an island of West Bengal India by the name Sagar Deep based on socio-economic and environmental aspects. The generation costs of SPV systems and conventional power has been compared to show how conventional power systems suffer from diseconomy when power needs to be transmitted to extremely remote locations. The social viability of SPV was apparent from a conspicuous improvement in commerce, trade, education and increased participation of women in activities other than household chores in the island [35].

It has bee concluded that there is no way one can afford to ignore assessment of the systems for their techno-economic feasibility as these parameters are location specific and the successful operation of the systems entirely depend on these parameters at a given region. It is also observable that systems which are uneconomical for a given load factor may become feasible for higher load factors. This opens up the discussion on what should be the ideal size, capacity factor and load factor range for which the system becomes feasible. Some of these questions were answered in the literature using optimization models. But it acts as a background for the design of the systems, which will be discussed in another section namely System Design Methods.

\section{Performance Evaluation}

A performance evaluation of solar photovoltaic system has been carried out using the available literature. Literature presents various methods for performance evaluation of SPV systems. Optimal performance of a particular SPV system depends upon the fact that how reliable are the different components that are used in that system. If the components used in the system are easily replaceable than this could have positive impact on the system performance.

System specific evaluation studies have also been highlighted the several usage related aspects. The evaluation of a nine year old solar home system and street lighting system in Indonesia is carried out and it is found 
that the failure rate of street lighting systems was high, although that the villagers had a positive opinion about these systems. Further, it was reported that the solar home systems performed well technically and the users were satisfied with the performance. However, in the course of time the configuration of the solar home systems had changed. Villagers had replaced the original strip lights with cheap locally made incandescent lamps and had replaced the initially installed 100 Ah capacity solar batteries with cheaper locally produced $70 \mathrm{Ah}$ capacity car batteries [36]. In a similar study, the failure of bypass diodes in solar battery charging stations (SBCS) in Thailand has been analyzed. The inclusion of bypass diodes in these systems created an unexpected failure mode when villagers wrongly connected their batteries with reverse polarity. In a survey of 31 stations, 18 stations were disabled by burnt-out bypass diodes [37]. The performance of a $4 \mathrm{~kW}$ grid connected wind/PV system with battery storage in Lowell has been reported [38]. It is reported that the power quality (total voltage distortion, frequency and voltage level) is within the acceptable limits at the point of connection to the grid i.e. connection of the system to the grid is not the point of concern. The system has a loss of power supply probability of one day in ten years. The study is based on the performance study of the practical system for two years. In this work primary resources (wind speed, irradiance) averaged over several years are helped in predicting system performance for a long period of time, the fluctuations in the resources from year to year, however, is a handicap in the determination of system component ratings that would satisfy a long-term objective like a loss of power supply probability at a minimum cost. A methodology [39] has been developed for small-scale hybridized solar PV-AC grid (HSPVACG) power system to operate with ac grid. This system consists of a photovoltaic array installed on the rooftop, a hybrid power controller (HPC) and an inverter. This newly developed (HPC) works in such a way that for a particular predetermined load the maximum available solar power is utilized and the remaining power is drawn from the AC grid. The load requirement and the power flow are continuously monitored. The power generated from solar panels is given preference over grid power such that the sum of the two powers equals to the required total load for the utilization of maximum solar power. This HSPVACG power system is best suited for operation during the daytime however a battery backup of two-hour duration can be incorporated for operation beyond sunshine. The system provides optimum economical use of solar PV power. This system is in fact can he substituted by the Invertor-batterey emergency power backup (IBEPP) which is widely being used in developing countries due to unreliable grid. These IBEPP consumes a large amount of electricity addition- ally, to keep it operating which ultimately loads the over burdened ac grid further. HSPVACG system produces pollution free green electricity, which is very attractive in urban environment. A hybrid Wind/Photovoltaic/Fuel Cell system has presented [40]. In this system, different energy sources in the system are linked through the AC link. The overall control and power management strategy for the proposed hybrid energy system is presented. The simulation model of the hybrid system is also developed using MATLAB/SIMULINK. The wind and PV are the main source of generation. The electrolyser acts as a dump load using any excess power available to produce H2. The Fuel Cell system is the backup generation and supplies power to the system when there is power deficit. The Fuel Cell is used to store the excess power during the off-peak period and to supply power to the system when there is deficit of power. The simulation results show the effectiveness of the overall power. An analytical approach for the well being assessment of small autonomous power systems with wind and solar energy sources has been developed [41]. This technique accounts for the uncertainties associated with solar irradiance, wind speed, demand, and outages of various generating units. The results obtained with the above analytical approach are compared with Monte Carlo Simulation technique and concluded that the proposed analytical method computes the system well-being indexes quite accurately. The developed methodology is computationally very efficient and the analytical approach requires much less amount of meteorological data than Monte Carlo Simulation. A techno-economic and environmental analysis for grid interactive solar photovoltaic power system of Lakshadweep islands has been developed [42]. In these islands the main source of electricity is diesel generators, the diesel being transported from the main land to produce over $9 \mathrm{MW}$ of electricity considering the remoteness of the island and the polluting nature of the existing plants, it is desirable to adopt a strategy to utilize available potential of non-polluting renewable energy sources for these ecologically sensitive islands. Use of hybrid PV/diesel system with battery can significantly reduce the dependence on solely available diesel resource if the sizing of the PV panel, diesel generator and PV array is done and demonstrated [43]. Although utilization of hybrid PV/diesel system with battery might not significantly reduce the total net present cost and cost of energy, it has been able to cut down the dependence on diesel. In addition, it also helps to reduce pollutants, such as carbon emission, thus reducing the green house effect. On the other hand, it was also proven that the use of hybrid PV/diesel system with battery would be more economical if the price of diesel increased significantly. With a projection period of 25 years and 6\% annual real interest rate, it is found that the use of hybrid PV/diesel 
system with battery could achieve significantly lower net present cost and cost of energy as compared to a standalone diesel system [43]. The detailed review and analysis of SPV literature pertaining to decentralized rural electrification is presented [44]. The interest in small scale electricity generation was underlined and major benefits and issues of using small scale distributed generation were discussed. A small scale PV power plant was described, a cash flow economic analysis was performed and market reactions under the new legislation in Greece were presented. And it was concluded that the elimination of time consuming license procedures, noticed during the implementation of first PV installations in Greece, will increase the PV penetration in Greek electricity market. Also, the appearance of PV module manufacturers in Greek market will lead to further reduction of PV cost making the PV technology cost competitive [45]. A few case studies has been presented for stand alone SPV systems to prove that the poor performance not only mean that the system is facing technical problems, but it might also be due to factors like mismatch between the generation potential and load factor, poor sizing and other systemic problems [46]. In this paper authors have examined the critical factors for failure of a stand-alone PV system. The work also highlights the limitation of current coefficients and developed new coefficients which make better performance indices over the existing ones for stand alone systems.

It has been concluded. For improving the performance of SPV systems selected components should be reliable and easily replaceable with the availability of cheap local technicians for maintenance and repair.

\section{Conclusions}

The following conclusions can be drawn from the thorough review of the literature available on techno-economic feasibility analysis of the SPV systems.

1) A generalized approach to assess suitability of SPV systems at a given location, based on techno-economic and environmental feasibility does not find good amount of coverage. However, if data based on system costs, operation and maintenance cost and other relevant cost details are made available along with the learning's from the case studies, the techno-economic feasibility assessment objective could be easily accomplished.

2) Conventional sizing methods such as mathematical empirical, numerical and analytical are used when all the metrological data related to a particular site is available however where these data's are not available these sizing methods could not be used and the use of artificial intelligence techniques are used in such cases.

3) It was found that the techno-economic assessment of SPV systems lacks the data related to economic parameters like payback period, net present value, rather they are generally based on annualized life cycle cost methods.

4) For a realistic estimate it is important to capture uncertainty in systems and hence stochastic modeling and simulation studies have to be encouraged in the field of energy studies.

5) System optimization techniques are useful for selecting ratings and types of components while designing systems for different applications.

6) Artificial intelligence techniques are very helpful for sizing of photovoltaic systems with some available data with sufficient accuracy and reliability particularly for isolated areas.

7) The cost of the PV system depends mainly on the local cost of components and hence varies from country to country and region to region and hence it is difficult to compare its life cycle cost with other types of centralised and decentralised systems for electricity generation.

8) In spite of the fact mentioned above techno-economic comparison of SPV systems helps in selecting proper method for electrification of unelectrified places.

9) Components should be selected for the SPV systems that are easily available so that replacement can be done easily and system performance is not affected because of unavailability of system components and hence the user satisfaction should be at highest level.

10) Solar Photovoltaic system is easy to install and SPV system has got the maximum potential in terms of electrical energy output among all the renewable energy sources.

11) Solar PV system can save substantial amount of diesel and also avoid excessive wear and tear of the Diesel Generator sets, therefore there is reduction in the cost of spare parts.

12) There are significant environmental advantages in the form of reduced emission due to lesser load on the Diesel Generator sets, whereas there is no pollution in the operation of grid interactive solar PV system.

13) Successful implementation of large scale SPV systems requires devising suitable policy measures after considerations of local support, institutional barriers and other social factors. This necessitates joint efforts from policy makers and modeling experts for clear representation of the energy problem and effective implementation of the solutions.

\section{REFERENCES}

[1] S. N. Singh, B. Singh and J. Ostergaard, "Renewable Energy Generation in India: Present Scenario and Future Prospects,” IEEE Power \& Energy Society General Meeting, Calgary, 26-30 July 2009, pp. 1-8.

[2] S. Bogdan and M. Salameh, "Methodology for Optimally Sizing the Combination of a Battery Bank and PV Array in a Wind/PV Hybrid System," IEEE Transactions on 
Energy Conversion, Vol. 11, No. 2, 1996, pp. 367-375. doi:10.1109/60.507648

[3] W. D. Kellogg, M. H. Nehrir, G. Venkataramanan and V. Gerez, "Generation Unit Sizing and Cost Analysis for Stand-Alone Wind, Photovoltaic, and Hybrid Wind/PV System," IEEE Transactions on Energy Conversion, Vol. 13, No. 1, 1998, pp. 70-76. doi:10.1109/60.658206

[4] A. N. Celik, "Techno-Economic Analysis of Autonomous PV-Wind Hybrid Energy Systems Using Different Sizing Methods,” Energy Conversion and Management, Vol. 44, No. 12, 2003, pp. 1951-1968. doi:10.1016/S0196-8904(02)00223-6

[5] M. M. Mahmoud and I. H. Ibrik, "Field Experience on Solar Electric Power Systems and Their Potential in Palestine,” Renewable and Sustainable Energy Reviews, Vol. 7, No. 6, 2003, pp. 531-543. doi:10.1016/S1364-0321(03)00070-4

[6] G. Bekele and B. Palm, "Feasibility Study for a Standalone Solar-Wind-Based Hybrid Energy System for Application in Ethiopia,” Applied Energy, Vol. 87, No. 2, 2010, pp. 487-495. doi:10.1016/j.apenergy.2009.06.006

[7] P. Arun, R. Banerjee and S. Bandyopadhyay, "Sizing Curve for Design of Isolated Power Systems," Energy for Sustainable Development, Vol. 11, No. 4, 2007, pp. 21-28. doi:10.1016/S0973-0826(08)60406-8

[8] P. Arun, R. Banerjee and S. Bandyopadhyay, "Optimum Sizing of Photovoltaic Battery Systems Incorporating Uncertainty through Design Space Approach,” Solar Energy, Vol. 83, No. 7, 2009, pp. 1013-1025. doi:10.1016/j.solener.2009.01.003

[9] E. S. Hrayshat, "Techno-Economic Analysis of Autonomous Hybrid Photovoltaic-Diesel-Battery System,” Energy for Sustainable Development, Vol. 13, No. 3, 2009, pp. 143-150. doi:10.1016/j.esd.2009.07.003

[10] A. Chaurey and T. C. Kandpal, “A Techno-Economic Comparison of Rural Electrification Based on Solar Home Systems and PV Microgrids,” Energy Policy, Vol. 38, No. 6, 2010, pp. 3118-3129. doi:10.1016/j.enpol.2010.01.052

[11] M. Uzunoglu, O. C. Onar and M. S. Alam, "Modelling, Control and Simulation of a PV/FC/UC Based Hybrid Power Generation System for Stand-Alone Applications,” Renewable Energy, Vol. 34, No. 3, 2009, pp. 509-520. doi:10.1016/j.renene.2008.06.009

[12] A. Mellit, S. A. Kalogirou, L. Hontoria and S. Shaari, "Artificial Intelligence Techniques for Sizing Photovoltaic Systems: A Review,” Renewable and Sustainable Energy Reviews, Vol. 13, No. 2, 2009, pp. 406-419. doi:10.1016/j.rser.2008.01.006

[13] M. R. Borges Neto, P. C. M. Carvalho, J. O. B. Carioca and J. F. Canafistula, "Biogas/Photovoltaic Hybrid Power System for Decentralized Energy Supply of Rural Areas," Energy Policy, Vol. 38, No. 8, 2010, pp. 4497-4506. doi:10.1016/j.enpol.2010.04.004

[14] B. K. Bala and S. A. Siddique, "Optimal Design of a PV-Diesel Hybrid System for Electrification of an Isolated Island Sandwitch in Bangladesh Using Genetic Al gorithm," Energy for Sustainable Development, Vol. 13, No. 3, 2009, pp. 137-142. doi:10.1016/j.esd.2009.07.002
[15] M. Sidrach-de-Cardona and L. M. Lopez, "Evaluation of a Grid-Connected Photovoltaic System in Southern Spain," Renewable Energy, Vol. 15, No. 1-4, 1998, pp. 527-530. doi:10.1016/S0960-1481(98)00218-3

[16] A. Schmitt, G. Huard and G. Kwiatkowsk, "PV-Hybrid Microplants and Mini-Grids for Decentralised Rural Electrification in Developing Countries,” EDF Research and development, France, 2006.

[17] N. Kaushika, N. K. Gautam and K. Kaushik, "Simulation Model for Sizing of Standalone Solar PV System with Interconnected Array," Solar Energy Materials and Solar Cells, Vol. 85, No. 4, 2005, pp. 499-519. doi:10.1016/j.solmat.2004.05.024

[18] A. Lietzmann, D. Frohler and K. Lietzmann, "Practical Experiences and Dimensioning in the Operation of Decentralized Energy Supply Stations, at RIO 5-World Climate \& Energy Event,” Proceedings of the International Conference, Rio de Janeiro, 2005.

[19] T. E. Drennen, J. D. Erickson and D. Chapman, "Solar Power and Climate Change Policy in developing Countries,” Energy Policy, Vol. 24, No. 1, 1996, pp. 9-16. doi:10.1016/0301-4215(95)00117-4

[20] G. C. Bakosa and M. Soursosb, “Techno-Economic Assessment of a Stand-Alone PV/hybrid Installation for Low-Cost Electrification of a Tourist Resort in Greece," Applied Energy, Vol. 73, No. 2, 2002, pp. 183-193. doi:10.1016/S0306-2619(02)00062-4

[21] J. L. Bernal-Agustin and R. Dufo-Lopez, "Economical and Environmental Analysis of Grid Connected Photovoltaic Systems in Spain,” Renewable Energy, Vol. 31, No. 8, 2006, pp. 1107-1128. doi:10.1016/j.renene.2005.06.004

[22] S. M. Shaahid and E. I. Amin, “Techno-Economic Evaluation of Off-Grid Hybrid Photovoltaic-Diesel Battery Power Systems for Rural Electrification in Saudi Arabia-A Way Forward for Sustainable Development," Renewable and Sustainable Energy Reviews, Vol. 13, No. 3, 2009, pp. 625-633. doi:10.1016/j.rser.2007.11.017

[23] M. Kolhe, S. Kolhea and J. C. Joshi, "Economic Viability of Stand-Alone Solar Photovoltaic System in Comparison with Diesel-Powered System for India,” Energy Economics, Vol. 24, No. 2, 2002, pp. 155-165. doi:10.1016/S0140-9883(01)00095-0

[24] M. M. Mahmoud and I. H. Ibrik, “Techno-Economic Feasibility of Energy Supply of Remote Villages in Palestine by PV-Systems, Diesel Generators and Electric Grid,” Renewable and Sustainable Energy Reviews, Vol. 10, No. 2, 2006, pp. 128-138. doi:10.1016/j.rser.2004.09.001

[25] D. B. Nelson, M. H. Nehrir and C. Wang, "Unit Sizing and Cost Analysis of Stand-Alone Hybrid Wind/PV/Fuel Cell Power Generation Systems,” Renewable Energy, Vol. 31, No. 10, 2006, pp. 1641-1656. doi:10.1016/j.renene.2005.08.031

[26] R. Kannan, K. C. Leong and R. Osman, "Life Cycle Assessment Study of Solar PV Systems: An Example of a 2.7 kWp Distributed Solar PV System in Singapore,” Solar Energy, Vol. 80, No. 5, 2006, pp. 555-563. doi:10.1016/j.solener.2005.04.008 
[27] A. Stoppato, "Life Cycle Assessment of Photovoltaic Electricity Generation,” Energy, Vol. 33, No. 2, 2008, pp. 224-232. doi:10.1016/j.energy.2007.11.012

[28] M. Raugei and P. Frankl, "Life Cycle Impacts and Costs of Photovoltaic Systems: Current State of the Art and Future Outlooks,” Energy, Vol. 34, No. 3, 2009, pp. 392399. doi:10.1016/j.energy.2009.01.001

[29] M. Kolhe, "Techno-Economic Optimum Sizing of a Stand-Alone Solar Photovoltaic System,” IEEE Transaction on Energy Conversion, Vol. 24, No. 2, 2009, pp. 511-519. doi:10.1109/TEC.2008.2001455

[30] M. EL-Shimy, "Viability Analysis of PV Power Plants in Egypt,” Renewable Energy, Vol. 34, No. 10, 2009, pp. 2187-2196. doi:10.1016/j.renene.2009.01.010

[31] S. S. Dihrab and K. Sopin, "Electricity Generation of Hybrid PV/Wind Systems in Iraq," Renewable Energy, Vol. 35, No. 6, 2010, pp. 1303-1307. doi:10.1016/j.renene.2009.12.010

[32] N. E. Mbaka, N. J. Mucho and K. Godpromesse, "Economic Evaluation of Small-Scale Photovoltaic Hybrid Systems for Mini-Grid Applications in Far North Cameroon,” Renewable Energy, Vol. 35, No. 10, 2010, pp. 2391-2398. doi:10.1016/j.renene.2010.03.005

[33] S. Rehman and L. M. Al-Hadhrami, "Study of a Solar PV/Diesel/Battery Hybrid Power System for a Remotely Located Population near Rafha, Saudi Arabia,” Energy, Vol. 35, No. 12, 2010, pp. 4986-4995.

[34] G. C. Bakos and N. F. Tsagas, “Technoeconomic Assessment of a Hybrid Solar/Wind Installation for Electrical Energy Saving,” Energy and Buildings, Vol. 35, No. 2, 2003, pp.139-145. doi:10.1016/S0378-7788(02)00023-3

[35] S. Chakrabarti and S. Chakrabarti, "Rural Electrification Programme with Solar Energy in Remote Region-A Case Study in an Island,” Energy Policy, Vol. 30, No. 1, 2002, pp. 33-42. doi:10.1016/S0301-4215(01)00057-X

[36] A. H. M. E. Reinders, Pramusito, A. Sudradjat, V. A. P. van Dijk, R. Mulyadi and W. C. Turkenburg, "Sukatani Revisited: On the Performance of Nine-Year-Old Solar Home Systems and Street Lighting Systems in Indonesia," Renewable and Sustainable Energy Reviews, Vol. 3, No. 1, 1999, pp. 1-47. doi:10.1016/S1364-0321(99)00004-0

[37] C. Greacen and D. Green, "The Role of Bypass Diodes in the Failure of Solar Battery Charging Stations in Thailand," Solar Energy Materials and Solar Cells, Vol. 70,
No. 2, 2001, pp. 141-149. doi:10.1016/S0927-0248(01)00017-4

[38] F. Giraud and Z. M. Salameh, "Steady-State Performance of a Grid-Connected Rooftop Hybrid Wind-Photovoltaic Power System with Battery Storage,” IEEE Transactions on Energy Conversion, Vol. 16, No. 1, 2001, pp. 1-7. doi:10.1109/60.911395

[39] I. Ashraf and A. Chandra, "Techno Economic Viability of a Rooftop Hybridized Solar PV-AC Grid Assisted Power System for Peak Load Management,” 2nd International Conference on Power Electronics Machines and Drives, Vol. 1, 2004, pp. 442-446.

[40] C. Wang and M. H. Nehrir, "Power Management of a Stand-Alone Wind/Photovoltaic/Fuel Cell Energy System," IEEE Transaction on Energy Conversion, Vol. 23, No. 3, 2008, pp. 957-967. doi:10.1109/TEC.2007.914200

[41] D. K. Khatod, V. Pant and J. Sharma, "Analytical Approach for Well-Being Assessment of Small Autonomous Power Systems with Solar and Wind Energy Sources," IEEE Transaction on Energy Conversion, Vol. 25, No. 2, 2010, pp. 535-545. doi:10.1109/TEC.2009.2033881

[42] I. Ashraf, A. Chandra and M. S. Sodha, "Techno-Economic and Environmental Analysis for Grid Interactive Solar Photovoltaic Power System of Lakshadweep Islands," International Journal of Engineering Research, Vol. 28, 2008, pp. 1033-1042.

[43] K. Y. Lau, M. F. M. Yousof, S. N. M. Arshad, M. Anwari and H. M. Yatim, "Performance Analysis of Hybrid Photovoltaic/Diesel Energy System under Malaysian Conditions,” Energy, Vol. 35, No. 8, 2010, pp. 3245-3255. doi:10.1016/j.energy.2010.04.008

[44] A. Chaurey and T. C. Kandpal, “Assessment and Evaluation of PV Based Decentralized Rural Electrification: An Overview," Renewable and Sustainable Energy Reviews, Vol. 14, No. 8, 2010, pp. 2266-2278. doi:10.1016/j.rser.2010.04.005

[45] G. C. Bakos, "Distributed Power Generation: A Case Study of Small Scale PV Power Plant in Greece,” Applied Energy, Vol. 86, No. 9, 2009, pp. 1757-1766. doi:10.1016/j.apenergy.2008.12.021

[46] D. P. Kaundinya, P. Balachandra and N. H. Ravindranath, "Grid-Connected versus Stand-Alone Energy Systems for Decentralized Power-A Review of Literature," Renewable and Sustainable Energy Reviews, Vol. 13, No. 8, 2009, pp. 2041-2050. doi:10.1016/j.rser.2009.02.002 